\title{
Relation between integral effect of sub-surface temperature variation $(I)$ and seismic effects
}

\author{
H. Jalal Kamali ${ }^{1}$, A. A. Bidokhti ${ }^{2}$, and H. Amiri ${ }^{1}$ \\ ${ }^{1}$ Physics Department, Shahid Bahonar University of Kerman, Kerman, Iran \\ ${ }^{2}$ Geophysics Institute, University of Tehran, Tehran, Iran
}

Received: 23 August 2009 - Revised: 5 October 2009 - Accepted: 6 October 2009 - Published: 5 November 2009

\begin{abstract}
There will be a change in the Earth's local subsurface thermal structure before and/or after an earthquake. In this work we have introduced a new parameter $(I)$ which relates integral effect of temperature variation and seismic activity. This parameter in its various forms integrates the temperature variations during one year before and after earthquake. Some recent earthquakes are chosen throughout Iran on Alps-Himalayas fault zone with magnitudes 4.5 and more. Subsurface temperatures up to one meter depth measured in nearby weather stations are used as there is no deeper data available. We found the new defined parameter $(I)$ has a direct relation with earthquakes magnitude $(M)$ and reverse relation with distance $(d)$ between earthquake focus and station in which temperature is measured. Suitable formulas for these relations are suggested regarding the magnitude ranges and time period with respect to the earthquake time. There may be a way to use this new parameter as a quake precursor.
\end{abstract}

\section{Introduction}

Earthquake prediction has always been an effect in many relevant researches, though there has been usually no desirable results. This is because of the complicated behaviour of Earth's mechanical and dynamical structure and a limitation of interior data. But there are reports on physical and even chemical variation during an earthquake which may relates many parameters to earthquake activities; e.g. changes in Radon flux (Ulomov and Mavashev, 1967), groundwater flow (Yamaguchi and Otaka, 1978), electrical resistivity (Mazella and Morrison, 1974; Quian, 1985)), vertical movements (Mogi, 1982 and temperature variation related to tectonic activities (Notsu et al., 1980; Shimamura et al., 1985;

Correspondence to: H. Jalal Kamali

(hjalalkamali@mail.uk.ac.ir)
Kitagawa et al., 1996; Hamza, 1997, 1998, 2001; Rezapour et al., 2007). Thermal anomalies on time and places of earthquakes are also reported by satellite studies with desirable resolution (Tronin, 1996, 2000; Tronin et al., 2002; Saraf and Choudhury, 2005; Chen et al., 2006).

In fact due to earthquake activities changes in Earth's local sub-surface resistivity, electric and magnetic potentials, Radon gas, stress and strain, friction, water flow and so on altogether cause change in local thermal structure. No matter how much each may affects the temperature, but the integration of their effects in time of earthquake can have some effect on sub-surface temperature. The key question is whether there is a parameter relating this thermal anomaly to the earthquake parameters. Here by introducing a parameter we test the seismic thermal anomaly for some earthquakes in Iran.

\section{The $I$ parameter}

Due to a shortage of data especially deep soil and water temperatures, the nearest earthquakes to weather stations are chosen. In these stations soil temperatures are measured only up to a maximum one meter. To define the parameter $I$ by which the variation of temperature (caused by earthquake activities) relates to the quake parameters the deadly Bam earthquake, south-east of Iran is chosen. This earthquake of magnitude 6.5 happened on 26 December 2003 and killed close to 40000 people.

Sub-surface temperatures measured in Bam weather station indicate that surface and atmospheric conditions have a smooth influence on deep temperatures (Fig. 1a) though the city is situated the desert. For more stability the time is chosen about sun rise (03:00 UT) during November 2002, a year before the earthquake. The nine years average temperature at one meter depth $\left(T_{a v}\right)$ with consideration of seasonal effects has a smooth sine like graph (Fig. 1b).

Published by Copernicus Publications on behalf of the European Geosciences Union. 


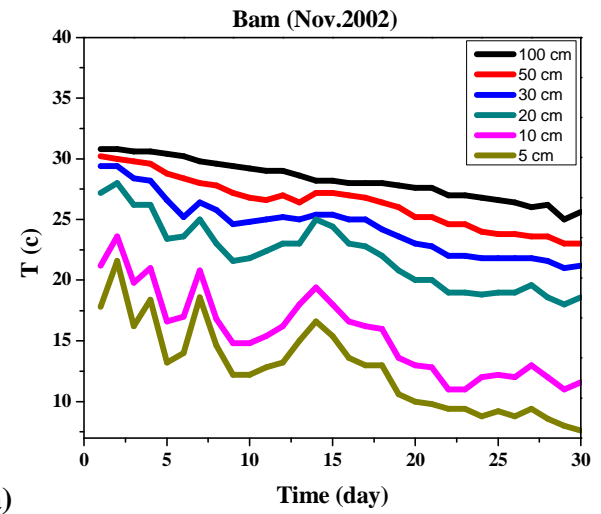

(a)

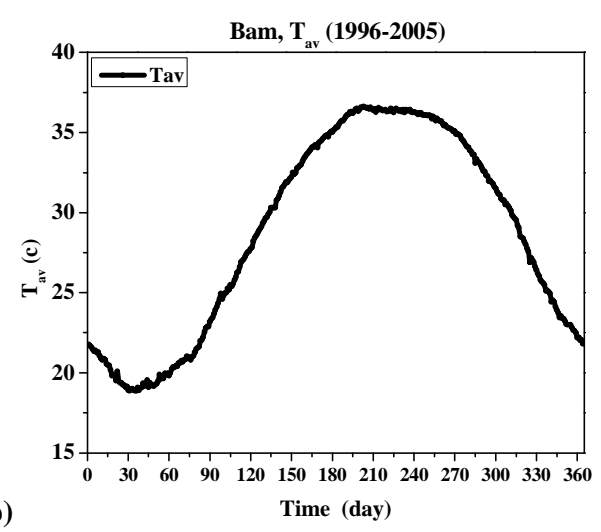

Fig. 1. (a) Temperature variation at 5, 10, 20, 30, 50, and $100 \mathrm{~cm}$ depth at 03:00 UT during November 2002. (b) A nine years average temperature at one meter depth in Bam.

Annual variation of temperature in this graph is due to heat conduction from the surface according to the Fourier's law;

$$
\begin{aligned}
& H=-k\left(\frac{\partial T}{\partial z}\right) \\
& \frac{\partial T}{\partial t}=\kappa\left(\frac{\partial^{2} T}{\partial z^{2}}\right)
\end{aligned}
$$

where $H$ is the ground heat flux, $T$ temperature, $k$ coefficient of thermal conductivity, $\kappa=k / \rho c$ is thermal diffusivity, $\rho$ density and $c$ is specific heat. These, subjected to a sinusoidal heat wave at the surface (with amplitude $T_{S}$ ) lead to relations for temperature at different depths and also surface heat flux;

$$
\begin{aligned}
& T(z, t)=\bar{T}+T_{s} \exp \left(-\frac{z}{D^{\prime}}\right) \cos \left(\omega t-\frac{z}{D^{\prime}}\right) \\
& H_{z=0}=\rho c(\kappa \omega)^{1 / 2} \cos \left(\omega t+\frac{\pi}{4}\right)
\end{aligned}
$$

where $\bar{T}=T(z \rightarrow \infty), \omega$ is wave angular frequency of heat wave, $t$ is time and $D^{\prime}=(2 \kappa / \omega)^{1 / 2}$ is damping depth (Arya,

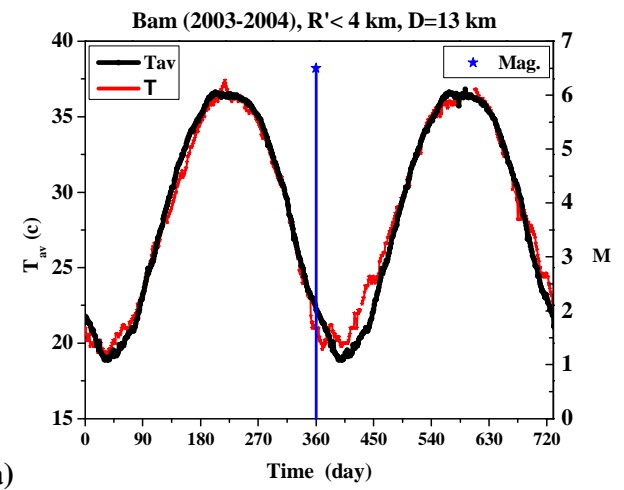

(a)

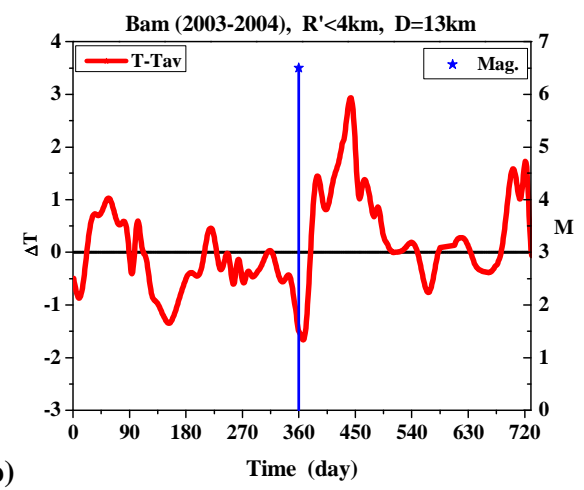

Fig. 2. (a) $T$ (temperature) and $T_{a v}$ (nine years daily average temperature) versus time ( $t$ ) during 2003-2004 one year before and a year after Bam disaster that is shown by ${ }^{*}$. (b) $\Delta T$ versus time in same period as $2 \mathrm{a}, M$ is earthquake magnitude, $D$ focus depth (hypocenter) and $R^{\prime}$ is the epicentral distance to the weather station.

1998). $D^{\prime}$ is the damping depth for daily temperature variation if rather small, typically 0.1 to $0.15 \mathrm{~m}$. So that the surface heat wave due to daily variation damps very quickly below the surface. Hence any changes in temperature in deeper parts are not due to short period surface heat wave.

We will therefore work on temperatures at one meter depth. To eliminate seasonal effects we detrend the record and hence acquire $\Delta T=T-T_{a v}$ which is a better indicator, where $T$ is temperature at one meter depth at the time $t$ and $T_{a v}$ is the daily mean trend temperature for nine years at the same depth (Fig. 2). One reason for the change of $\Delta T$ may be seismic activities especially during time period of around of an earthquake. For example, considerable $\Delta T$ anomaly can be seen during the time period of Bam (26 December 2003) earthquake (Fig. 2). There is an advantage here that this temperature anomaly consists of the integrated effects of all physical processes that may change due to the seismic activities and affect the sub-surface temperature.

In order to compare the temperature variation due to seismic processes with ones resulting from seasonal fluctuations and other effects, the Fourier filtering applied to the $T$ (quake year temperatures) and $T_{a v}$ functions and their frequency 


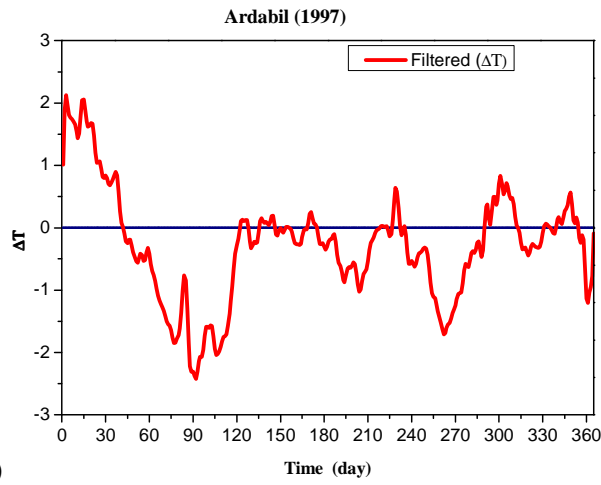

(a)

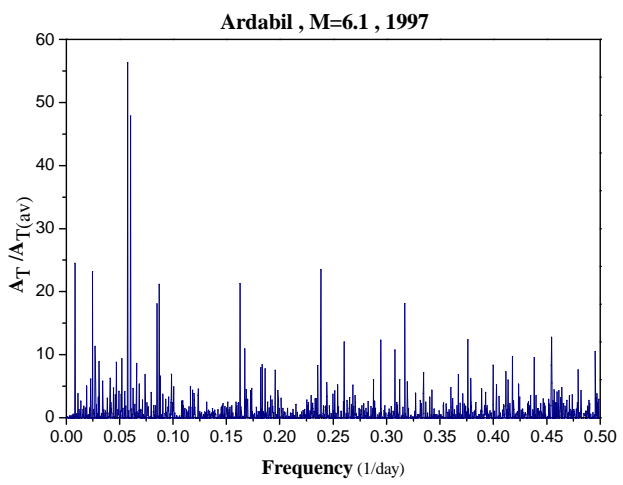

(b)

Fig. 3. (a) Filtered temperature variation with time during the year of earthquake for Ardabil quake (28 February 1997, with magnitude of 6.1). (b) Fourier transform of $T$ signal relative to the Fourier transform of $T_{a v}$ for this earthquake.

spectrum obtained. Comparison showed that the relative amplitude of the spectrum components corresponding to the short-term variations in the quake year is greater than ones associated with seasonal fluctuations that have a longer period. As an example, Fig. 3 depicts this analysis for Ardabil intense quake (28 February 1997 with magnitude of 6.1). Part (a) of Fig. 3 shows the temperature variation among the year of earthquake passed through a low pass Fourier filter. Figure $3 \mathrm{~b}$ shows the Fourier transform of $T$ expressed as the amplitude of its frequency components relative to the ones of the Fourier transform of the mean annual temperature signal $\left(T_{a v}\right)$. It is evident from the spectrum that the components which, regarding their periods, could be attributed to seismic effects are one or two order of magnitudes larger than ones due to seasonal fluctuations that have a distinct and larger period (lower frequencies). This can be considered as a confirmation of the proposition that around the time of earthquake there is a distinguishable subsurface temperature variation.

To find the relation between this temperature anomaly and the seismic activities the integration of $\Delta T(t)$ function (such as Fig. 2b) is used. We have used time period of a year before and one after the earthquake for the symmetry of seasonal effects on both side of the main quake time $\left(t_{q}\right)$. This may also take account of the whole physical parameters contribution in thermal energy variation and all shocks in an earthquake. There upon we can define $I_{b}, I_{a}$, and $I_{b a}$ as integration on time periods of before, after and whole time as;

$$
\begin{aligned}
& I_{b}=\int_{-365}^{t_{q}} \Delta T(t) d t \\
& I_{a}=\int_{t_{q}}^{+365} \Delta T(t) d t \\
& I_{b a}=\int_{-365}^{+365} \Delta T(t) d t
\end{aligned}
$$

where $t_{q}=0$.

\section{Data analysis}

Seventeen earthquakes with magnitude of 4.5 and larger (1996-2005) are selected (Table 1) all over Iran plateau (Fig. 4) in a manner to find meteorological data stations nearby. Table 1 consists of earthquakes specifications including locus, date, magnitude (Mag.) and hypocentral depth $(D)$ with sites of data stations.

Some 62000 temperature data at different soil depths measured by 17 weather stations near epicenters are analysed. Graphs of $f(\Delta T, t)$ functions for all 17 earthquakes are drawn. Distances from stations to epicenters $\left(R^{\prime}\right)$ and to hypocenters $(d)$ are calculated by plane and spherical geometry. The Hayford geoid mean radius $(6376.65 \mathrm{~km})$ for Iran is used. The resulted values of $I$ parameter, $R^{\prime}$ and $d$ for all these earthquakes are tabulated in Table 2.

In this table two key variable parameters $d$ and $M$ affect $I$. A logical assumption is direct relationship of $I$ with $M$ and in reverse with $d$. Therefore, as a first step the variations of $I_{b a} / M$ is plotted with respect to $1 / d$ (or $I$ versus $M / d$ ). This is shown in Fig. 5 indicating a meaningful relation. A marked point in this graph is the separation of intense earthquakes, $M>5.8$ (shown by squares) from small ones, $4.5<M<5.3$ (shown by circles). This may indicates that there is a more meaningful relationship of $I$ with $M$ than $d$.

The best fit for the graph (Fig. 5) confirms the accuracy of our assumption that $I \propto(M / d)$, among many attempts. In addition, there is a better correlation between points related to the large earthquakes as it was expected. This is due to the fact that larger earthquakes have probably more effects on temperature variation and cause larger thermal anomalies. Thereafter we study two groups of earthquakes separately.

\subsection{Intense earthquakes $(M>5.8)$}

Among the earthquakes considered (Table 2), there are 4 with magnitudes larger than 5.8 (Ardabil, Bam, Ghaen, and Zarand earthquakes). Graph of $I$ versus $M / d$ for these earthquakes are shown in Fig. 6 a for all three periods of time $\left(I_{b}\right.$, 
Table 1. Earthquakes with magnitude of 4.5 and larger happened in Iran 1996-2005 selected for this study with sites of data stations.

\begin{tabular}{lllrrllll}
\hline No. & City & Lon. & Lat. & Date & Mag. & $\begin{array}{l}D \\
(\mathrm{~km})\end{array}$ & Lon. Sta. & Lat. Sta. \\
& & & & & & \\
\hline 1 & Ardabil & 48.07 & 38.11 & 28 Feb 1997 & 6.1 & 12 & 48.283 & 38.25 \\
2 & Bam & 58.38 & 29.08 & 26 Dec 2003 & 6.5 & 13 & 58.35 & 29.1 \\
3 & Bandare Daier & 51.69 & 27.8 & 13 Sep 2000 & 5 & 15 & 51.93 & 27.83 \\
4 & Bushehr & 51.17 & 28.9 & 2 Mar 2004 & 5.1 & 15 & 50.83 & 28.98 \\
5 & Dehloran & 46.99 & 32.86 & 26 May 1997 & 4.6 & 20 & 47.27 & 32.68 \\
6 & Ghaen & 59.43 & 33.92 & 25 Jun 1997 & 5.9 & 17 & 59.17 & 33.72 \\
7 & Jiroft & 57.7 & 28.46 & 25 May 1999 & 4.5 & 30 & 57.8 & 28.58 \\
8 & Kahnouj & 57.72 & 27.98 & 6 Jul 2003 & 5 & 22 & 57.7 & 27.97 \\
9 & Kangan Jam & 52.26 & 27.66 & 15 Feb 2004 & 4.6 & 15 & 52.22 & 27.49 \\
10 & Kashmar & 58.21 & 35.24 & 2 Feb 2000 & 5.3 & 23 & 58.47 & 35.2 \\
11 & Kermanshah & 47.35 & 34.49 & 24 Apr 2002 & 4.8 & 25 & 47.15 & 34.35 \\
12 & Khoor Birjand & 58.2 & 33.13 & 19 Jun 2005 & 5.2 & 15 & 58.43 & 32.93 \\
13 & Lordegan & 50.83 & 31.62 & 15 Jun 1998 & 5.2 & 25 & 50.82 & 31.52 \\
14 & Mianeh & 47.8 & 37.35 & 26 Sep 2005 & 4.8 & 16 & 47.7 & 37.45 \\
15 & Nehbandan & 59.8 & 31.55 & 23 Oct 2000 & 5.3 & 37 & 60.03 & 31.53 \\
16 & Torbate Jam & 60.75 & 35.41 & 3 Jul 2003 & 5.2 & 15 & 60.58 & 35.25 \\
17 & Zarand & 56.76 & 30.8 & 22 Feb 2005 & 6.4 & 14 & 56.57 & 30.8 \\
\hline
\end{tabular}

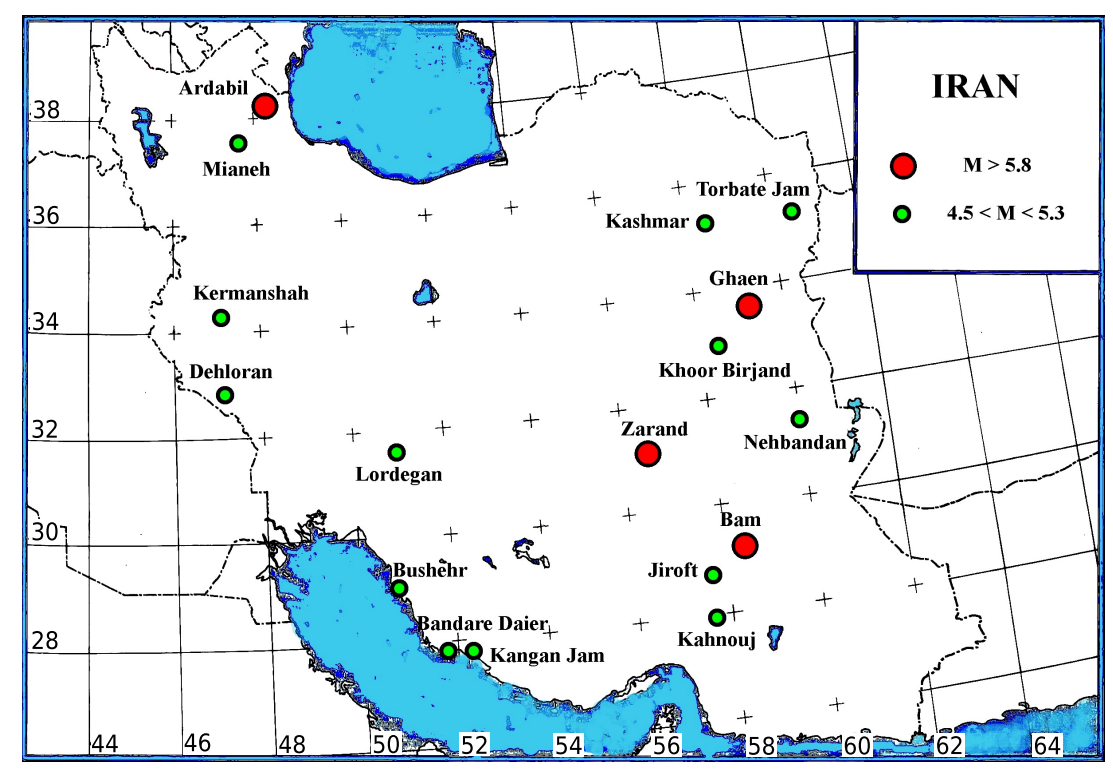

Fig. 4. Sites of earthquakes (Table 1) on Iran's map.

$I_{a}$, and $\left.I_{b a}\right)$. In this graph the Bam earthquake has the closest epicentral distance $\left(R^{\prime}=3.7 \mathrm{~km}\right)$ to the Bam weather station (Table 2). Eliminating the Bam earthquakes from Fig. $6 \mathrm{a}$ leads to a better correlation between the other three earthquakes in this group (Fig. 6b).

The best fitting point for these three (Ardabil, Ghaen and Zarand) earthquakes is nearly straight lines with coefficient of determination $R^{2}=1$. A considerable point in these two graphs (Fig. 6) is difference between slope of lines related to $I_{b}$ (before earthquakes) and $I_{a}$ (after earthquakes). More inclination in $I_{a}$ indicate more increase in temperature variation or thermal anomaly after earthquakes. This has also been reported by satellite studies (Tronin, 2002; Saraf, 2005; Chen, 2006). Anyhow, what we can say that $I$ is probably related to seismic activities and may be considered as an earthquake indicator. 
Table 2. Calculated $I$ parameters, epicentral $\left(R^{\prime}\right)$ and hypocentral $(d)$ distances together with magnitude (Mag) and hypocentral depths $(D)$ of earthquakes in Table 1.

\begin{tabular}{llllllrrr}
\hline No. & City & Mag & $\begin{array}{l}R^{\prime} \\
(\mathrm{km})\end{array}$ & $\begin{array}{l}D \\
(\mathrm{~km})\end{array}$ & $\begin{array}{l}d \\
(\mathrm{~km})\end{array}$ & $I_{b}$ & $I_{a}$ & $I_{b a}$ \\
\hline 1 & Ardabil & 6.1 & 24.6 & 12 & 27.1 & -139.8 & -194.9 & -334.7 \\
2 & Bam & 6.5 & 3.7 & 13 & 13.5 & -87.7 & 177.2 & 89.5 \\
3 & Bandare Daier & 5 & 23.8 & 15 & 28.2 & 251.8 & 34.8 & 286.5 \\
4 & Bushehr & 5.1 & 34.2 & 15 & 37.4 & 94.2 & -188.5 & -94.3 \\
5 & Dehloran & 4.6 & 32.9 & 20 & 38.5 & 6.9 & -269.9 & -263.1 \\
6 & Ghaen & 5.9 & 32.7 & 17 & 36.9 & -284 & -296.9 & -580.9 \\
7 & Jiroft & 4.5 & 16.5 & 30 & 34.3 & -21.5 & 93.9 & 72.4 \\
8 & Kahnouj & 5 & 2.3 & 22 & 22.1 & 268.6 & 199.3 & 468 \\
9 & Kangan Jam & 4.6 & 19.3 & 15 & 24.4 & 157.3 & 172.7 & 330 \\
10 & Kashmar & 5.3 & 24 & 23 & 33.3 & 53.4 & 97.7 & 151.1 \\
11 & Kermanshah & 4.8 & 24.1 & 25 & 34.7 & 185.9 & -64.8 & 121.1 \\
12 & Khoor Birjand & 5.2 & 30.9 & 15 & 34.3 & -343.4 & 169.6 & -173.8 \\
13 & Lordegan & 5.2 & 11.2 & 25 & 27.4 & -88.6 & 213.5 & 125 \\
14 & Mianeh & 4.8 & 14.2 & 16 & 21.4 & 52.5 & 306.8 & 359.3 \\
15 & Nehbandan & 5.3 & 21.9 & 37 & 43 & 120.3 & 117.3 & 137.6 \\
16 & Torbate Jam & 5.2 & 23.5 & 15 & 27.9 & -5.1 & 119.4 & 114.3 \\
17 & Zarand & 6.4 & 18.1 & 14 & 22.9 & -102.3 & -63.5 & -165.8 \\
\hline
\end{tabular}

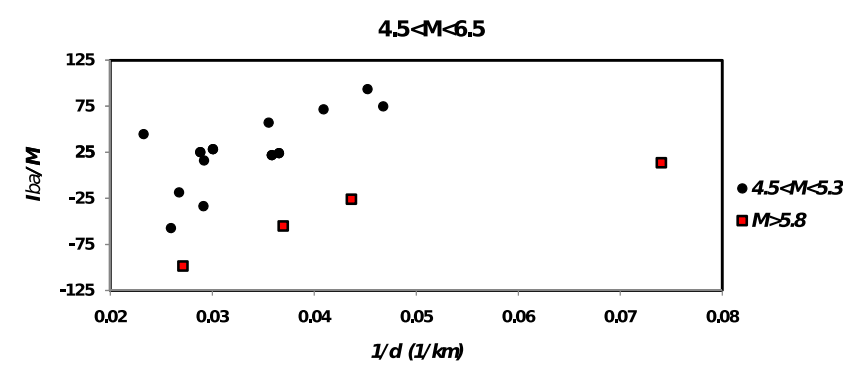

Fig. 5. Graph of $I_{b a}$ variation with $M$ and $d$, magnitude and direct distance station to hypocenter (Table 2). Larger earthquakes $(M>5.8)$ are shown by squares and small ones by circles.

\subsection{Small earthquakes $(4.5<M<5.3)$}

Earthquakes studied in the range of magnitude 4.5 to 5.3 (Table 2) are Bandare Daier, Bushehr, Dehloran, Jiroft, Kahnouj, Kangan Jam, Kashmar, Kermanshah, Khoor Birjand, Lordegan, Mianeh, Nehbandan, and Torbate Jam. The $I$ parameter in this group is also related to $M / d$, although not as clearly as the intense group (Fig. 7). The correlation is much better for $I_{a}$ (and hence $I_{b a}$ ) as is expected. This is due to more energy release and considerable temperature variation after earthquake than before. This also indicates the difference between $I_{a}$ and $I_{b}$ as the indication of thermal variation after and before earthquakes.

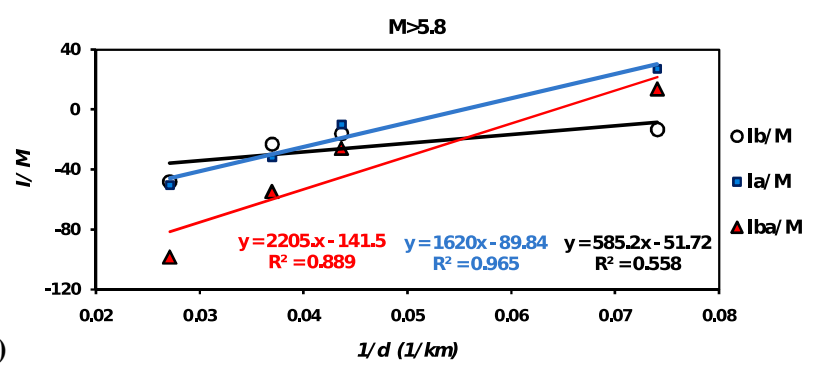

(a)

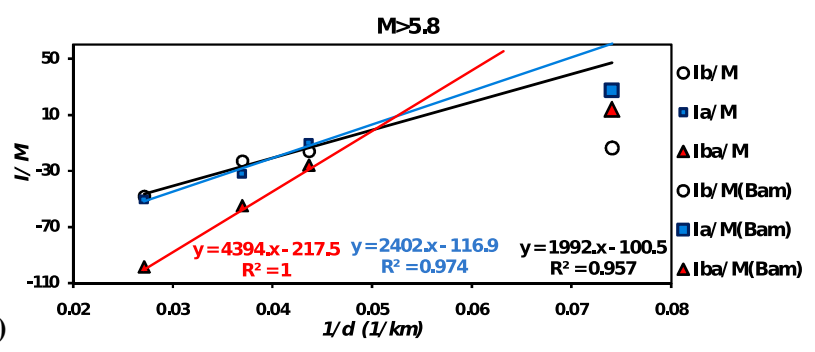

Fig. 6. (a) Graphs of $\left(I_{b}, I_{a}, I_{b a}\right)$ versus $M / d$ for earthquakes with magnitude larger than 5.8. The lines formula and coefficient of correlation $\left(R^{2}\right)$ are shown. (b) Same as (a) with elimination of Bam earthquake (from fitting procedure).

Due to smaller effects of small earthquakes on sub-surface temperature variation it may be affected by surface seasonal conditions. This may be a difficulty for correlation of small earthquakes of Fig. 7. 
(a)

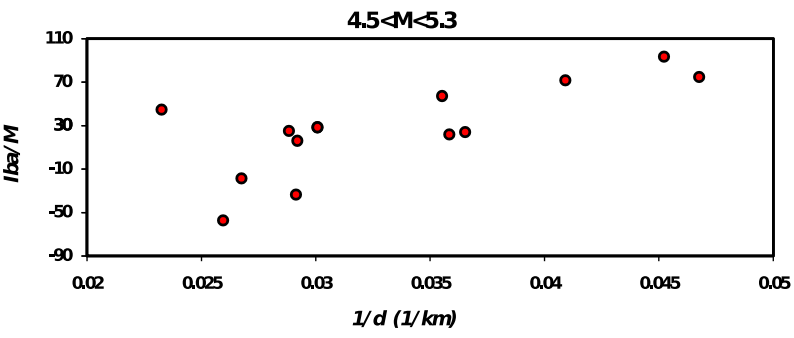

(b)

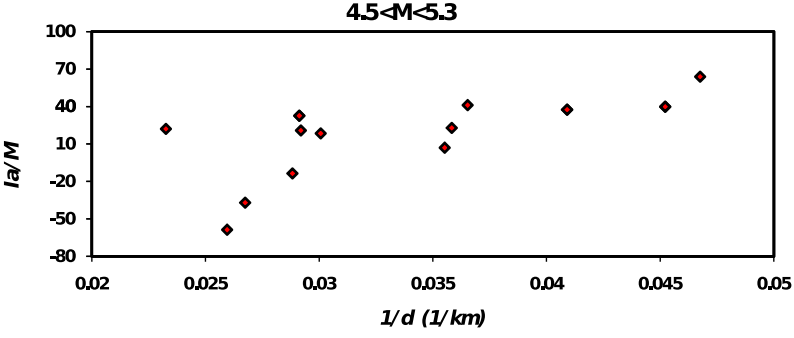

(c)

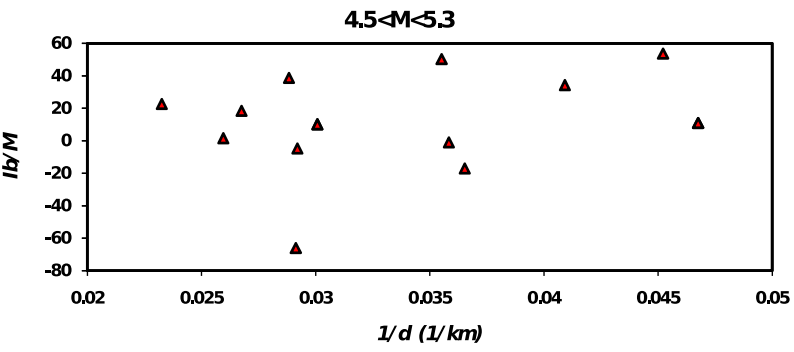

Fig. 7. Same as Fig. 6 for earthquakes of $4.5<M<5.3$.

\section{Conclusions}

Despite the variant surface conditions it seems seismic activities affect sub-surface temperatures as shallow as one meter up to some distances from epicenters. Data temperature from the nearest weather stations to 17 earthquake epicenters all over Iran plateau indicate considerable temperature deviation from long period average values $\left(\Delta T=T-T_{a v}\right)$ in time of earthquakes. There appears that at least for some earthquake as Bam which occurred in winter time there is a reduction in temperature before the quake. If water table before the quake is lowered due to seismic effects, colder near surface air may inter the ground through the pores and leads to temperature drop. After the quake the reverse could occur as we have a temperature rise. These require further study.

A new parameter $I$ as the integration of $\Delta T(t)$ on time periods around earthquake time is defined. It is shown that $I$ is logically related to seismic parameters. Data analysis indicates a direct relation of $I$ with $M$ (earthquake magnitude) and inverse relation with $d$ (distance to hypocenter). We suggest the following suitable formula for Iran plateau to relate
Table 3. Values of $\alpha, \beta$ and $R^{2}$ for earthquakes of $M>5.8$ shown in Fig. 6a including catastrophic Bam earthquake (+) and Fig. 6b without Bam earthquake (-).

\begin{tabular}{lccll}
\hline Diagram & $\begin{array}{c}\text { Bam } \\
\text { earthquake }\end{array}$ & $\alpha$ & $\beta$ & $R^{2}$ \\
\hline$I_{b} / M$ vs. $1 / d$ & - & 1992 & -100.5 & 0.957 \\
$I_{a} / M$ vs. $1 / d$ & - & 2402 & -116.9 & 0.974 \\
$I_{b a} / M$ vs. $1 / d$ & - & 4397 & -217.5 & 1 \\
& & & & \\
$I_{b} / M$ vs. $1 / d$ & + & 585.2 & -51.72 & 0.558 \\
$I_{a} / M$ vs. $1 / d$ & + & 1620 & -89.84 & 0.965 \\
$I_{b a} / M$ vs. $1 / d$ & + & 2205 & -141.5 & 0.889 \\
\hline
\end{tabular}

thermal variations to seismic parameters;

$\frac{I}{M}=\alpha\left(\frac{1}{d}\right)+\beta$

or

$I(T, t)=\alpha \frac{M}{d}+\beta M$

where $\alpha$ and $\beta$ values are defined in Table 3 depending on time periods with respect to earthquakes time $\left(I_{b}, I_{a}\right.$ and $I_{b a}$ ). The coefficient of determination $R^{2}$ close to one indicates a good certainty of relations. Further studies may concentrate on deeper temperature data for more accuracy and better correlation. Furthermore we may try to find that whether there is a way that $I_{b}$ as a pre-earthquake thermal anomaly indicator can be used as a precursor.

Acknowledgements. The seismological and meteorological data used in this work were obtained through kindly help of the International Institute of Earthquake Engineering and Seismology (IIEES) and Islamic Republic of Iran's Meteorological Organization (IRIMO), respectively.

Edited by: M. E. Contadakis

Reviewed by: O. Molchanov and L. Telesca

\section{References}

Arya, S.: Introduction to Micrometeorology, Academic Press, 1998. Chen, H., Parnel, J., and Gang, Z.: Large-scale seismic thermal anomaly linked to hot fluid expulsion from a deep aquifire, J. Geochem. Explor., 89, 53-56, 2006.

Hamza, V. M.: Thermal anomalies induced by tectonic fluid flows: a method of investigating physical processes in earthquake source regions, Bull. Seismol. Assoc. Far east, 3, 60-84, 1997.

Hamza, V. M.: Models of short-lived thermal pulses generated by tectonic fluid flow in the upper crust, in: Microtemprature Signals of the earth crust, edited by: Buntebarth, G., Zellerfeld, Germany, Papierflieger, Clausthal, 1998. 
Hamza, V. M.: Tectonic leakage of fault bounded aquifers subject to non-isothermal recharge:a mechanism generating thermal, Phys. Earth Planet. In., 126, 163-177, 2001.

Kitagawa, Y., Koizumi, N., and Tsuskuda, T.: Comparision of post-seismic groundwater temperature changes with earthquakeinduced volumetric strain release: Yudani hot spring, Japan, Geophys. Res. Lett, 23, 3147-3150, 1996.

Mazella, A. and Morrison, F.: Electrical resistivity variations associated with earthquakes on the San Andreas fault, Science, 185, 855 pp., 1974.

Mogi, K.: An interpretation of leveling data before the Niigata eartquake of 1964, Japan, J. Seismol. Soc. Jpn., 35, 478-482, 1982.

Notsu, K., Abiko, T., and Wakita, H.: Co-seismic temperature change of well water related to volcanic activities of the Usu volcano, J. Phys. Earth, 28, 617-624, 1980.

Quian, J.: Regional study of the anomalous change in apparent resistivity before the Tangshan earthquake $(\mathrm{m}=7.8,1976)$ in China, Pure Appl. Geophys., 122, 901-920, 1985.

Rezapour, N., Bidokhti, A., and Fattahi, M.: Study of some relationship between thermal properties of the ground and earthquake activity in Alborz region, in: International earthquake symposium Kocaeli, Turkey, 2007.
Saraf, A. K. and Choudhury, S.: Thermal Remote Sensing Technique in the Study of Pre-Earthquake Thermal Anomalies, J. Ind. Geophysics, 9, 197-207, 2005.

Shimamura, H., Ino, M., Hikawa, H., and Iwasaka, T.: Groundwater micro-temperature in earthquake regions, Pure Appl. Geophys., 122, 933-946, 1985.

Tronin, A.: Thermal IR Satellite sensor data application for earthquake research in China, Int. J. Remote Sens., 21, 3169-3177, 2000.

Tronin, A. A.: Satellite thermal survey - a new tool for the studies of seismoactive regions, Int. J. Remote Sens., 17, 1439-1455, 1996.

Tronin, A. A., Hayakawa, M., and Molchanov, O.: Thermal IR satellite data application for earthquake research in Japan and China, J. Geodyn., 33, 519-534, 2002.

Ulomov, V. and Mavashev, B.: A precursor of a strong tectonic earthquake, Dokl. Akad. Sci. USSR Earth Sci. Sect, 179, 9-11, 1967.

Yamaguchi, R. and Otaka, S.: Precursory changes in water level at Funabara and Kakigi before the Izu-Oshima-Kikai earthquake of 1978, Bull. Earthquake Res. Inst. Univ. Tokyo, 53, 841-854, 1978 . 